\title{
OBSERVACIONES EN TORNO AL POBLAMIENTO CASTREÑO DE LA EDAD DEL HIERRO EN ASTURIAS (1)
}

\author{
REMARKS ABOUT THE CASTREÑO SETTLEMENT IN THE ASTURIAN IRON AGE
}

\author{
SERGIO RÍOS GONZÁLEZ (*) \\ CÉSAR GARCÍA DE CASTRO VALDÉS (**)
}

\section{RESUMEN}

La investigación actual sobre la Edad del Hierro en Asturias (Norte de España) se encuentra inmersa en un debate sobre cronologías y tradiciones histórico-culturales que no contribuye en absoluto al conocimiento positivo de la realidad histórica correspondiente. Las posiciones teóricas previas condicionan tanto los procedimientos de la excavación como su ulterior interpretación. Este trabajo pretende establecer un balance crítico de resultados y contribuir a la redefinición de los problemas.

\begin{abstract}
Current research on the Iron Age in Asturias (Northern Spain) is involved in a discussion on chronologies and cultural traditions, which contributes nothing to positive knowledge of the corresponding historical reality. Previous theoretical positions determine not only the excavation methods but also the subsequent interpretation. This paper tries to establish a critical evaluation of results and to propose a new look at the problems.
\end{abstract}

Palabras clave: Edad del Hierro. Asturias. Castros. Cultura castreña.

Key words: Iron Age. Asturias. Hillforts. Castreña Culture of Northern Spain.

(*) Otero, $6 \mathrm{~A}, 5 .^{\circ} \mathrm{B} .33008$ Oviedo.

(**) Avda. de la Costa, 6, 4. ${ }^{\circ}$ P. 33201 Gijón.

Este artículo fue remitido en su versión final el 2-IV-2001.

(1) Entregada la versión definitiva de este artículo, tuvo lugar el fallecimiento del profesor doctor José Luis Maya González. Como en este artículo se hace referencia constante - y en ocasiones crítica- a los postulados teóricos e interpretaciones arqueográficas defendidas por este investigador, ambos autores queremos hacer constar nuestro pesar por su inesperado y desdichado fallecimiento, el respeto que siempre nos causó su talla científica y humana, y el recuerdo amable que de su obra y persona nos queda.

\section{INTRODUCCIÓN}

Puede establecerse en 1982 el comienzo de una nueva etapa en el estudio de los asentamientos castreños asturianos, ya que en la fecha se inician proyectos de excavaciones sistemáticas con protocolos científicos homologados a los que en la década precedente ya se estaban aplicando en yacimientos paleolíticos de la región. Se retoman en ese año las investigaciones en yacimientos conocidos de antiguo, como el Castelón de Coaña (Villacondide, Coaña), y en otros en los que apenas se había practicado algún sondeo, como la Campa Torres (Jove, Gijón), se abordó su excavación continuada, sin interrupción hasta la actualidad (Maya, 1988). Tanto el yacimiento gijonés como una serie de asentamientos en el valle del Río Navia (Mohías, San Isidro, Pico da Mina, Chao Samartín, La Escrita y el propio Castelón de Coaña) fueron objeto de investigación arqueológica, abarcando desde la prospección territorial detallada hasta la excavación extensiva (Carrocera, 1987 y ss). En 1987 se iniciaron las exploraciones y excavaciones arqueológicas en yacimientos castreños en torno a la ría de Villaviciosa (Camino, 1992). Paralelamente, la administración autonómica financió el inventario arqueológico regional, lo que permitió incrementar en más de un centenar el número de yacimientos castreños inventariado por José Manuel González y Fernández Valles (1966, 1973; Ríos y García de Castro, 1998: 23-27). A diferencia de otras regiones españolas, la arqueología de gestión no ha tenido posibilidad de intervenir en asentamientos castreños más que en dos ocasiones. $\mathrm{La}$ primera de ellas afectó al Castillo de San Martín (Soto del Barco), de la que se dispone exclusivamente de meras alusiones y algunas fotografías (Carrocera, 1995a: 59; Carrocera y Camino, 1996: 
58,60 ), y la segunda al Castiellu de Llagú (Latores, Oviedo).

Paradójicamente, la presencia de información procedente de estos poblados asturianos en el debate y estado de la cuestión sobre la Edad del Hierro peninsular es prácticamente inexistente, hecho que no ha pasado inadvertido a algunos investigadores (Fernández Posse, 1998: 216-217). Ello es debido, entre otras razones, a la escasa información objetiva publicada y a la aún menor difusión de estos informes, casi en su totalidad aparecidos en publicaciones locales o regionales. Por nuestra parte, hemos publicado una síntesis de resultados y cuestiones pendientes (Ríos y García de Castro, 1998), en la que se ofrece un panorama general referido a la fecha. En ella sintetizábamos los tres enfoques epistemológicos que han regido la investigación castreña en Asturias: histórico-cultural, antropológico-cultural y etnohistórico (Ríos y García de Castro, 1998: 9-22). Podemos afirmar por ello que hasta el momento la primera de estas perspectivas es la dominante. En efecto, en la investigación arqueológica han primado las descripciones arqueográficas del registro mobiliar (cerámicas y materiales metálicos), con un notable descuido de las estructuras de habitación y su ordenación en el poblado. En los momentos iniciales de la investigación, la cronología y periodización de cada asentamiento se deducía de la información derivada de estas clasificaciones, apoyada por algunas dataciones radiocarbónicas. Los debates surgidos a raíz de estas propuestas han dado lugar a que las fechas aisladas hayan sido sustituidas por series de dataciones radiocarbónicas calibradas. De este modo la investigación parece haberse centrado en la discusión sobre la oportunidad, homogeneidad, coherencia y posibilidad histórica de dichas series, que han asumido un papel casi autónomo en la discusión de cada yacimiento (Cuesta et alii, 1996: 260-264). La preocupación parece residir en obtener cronologías, a poder ser cada vez más antiguas, en una a modo de carrera por apropiarse de la "esencia" prerromana de la región. Efectivamente, no escapa al lector avisado que la valoración de las ocupaciones de un yacimiento está teñida de connotaciones extracientíficas. La ocupación romana, que histórica y lógicamente fue primeramente documentada, apenas ha requerido la atención de la investigación en la última década, centrándose la polémica y esfuerzos en definir las ocupaciones anterromanas, aureoladas en ocasiones del "prestigio indigenista". A ello se suma un afán prematuro por periodizar y orga- nizar el magro registro arqueológico en fases generales que intentan adaptarse a esfuerzos semejantes, bien del Noroeste, bien del valle del Duero, así como por establecer las filiaciones histórico-culturales de dicho registro. Es fácil percibir en estos discursos la herencia de los planteamientos historiográficos derivados de la exégesis tradicional de las fuentes grecolatinas sobre el norte de la Península Ibérica. Así, la división administrativa del actual territorio asturiano bajo el Imperio Romano en tres conventus, lucensis, asturum y cluniensis, es traducida sin reparo a términos etnológicos, que a su vez se proyectan sobre el registro arqueológico castreño anterior a la romanización (Maya, 1988: 13-14; 297-298; 1989: 26). De este modo, los castros del valle del Navia presentarían relaciones de parentela con la llamada "cultura castreña del NO"; los yacimientos de la Asturias central (Campa Torres) reflejarían inequívocas asociaciones con el grupo Soto de Medinilla (Maya y Cuesta, 1992: 149; Maya, 1994); y los yacimientos de la Asturias oriental vendrían adscribiéndose sin problema al grupo Miraveche-Monte Bernorio. A lo largo de la última década, han ido levantándose opiniones discrepantes con este consenso tradicionalmente admitido, sin cuestionar sin embargo la epistemología subyacente. Así, se ha discutido que los yacimientos del valle del Navia, al Oeste de la región, presenten relaciones con la cultura castreña galaica, apuntándose para este sector vínculos con el Occidente de la meseta Norte (Carrocera, 1990c). En cuanto al área oriental, las opiniones han ido matizando la referencia al grupo Miraveche-Monte Bernorio con la apreciación de un proceso de celtiberización, que avanzaría desde el foco del oriente de la Meseta Norte hacia el Noroeste, diluyéndose progresivamente (Maya, 1994: 308-311; 1996). No todos los investigadores, sin embargo, han aceptado las relaciones del registro de la Campa Torres con el grupo Soto de Medinilla II (Carrocera, 1994: 215; Camino, 1995a: 123-124; Carrocera y Camino, 1996: 58-59). La búsqueda de paralelos para los elementos más definidos tipológicamente del registro, fundamentalmente metálicos, ha provocado que la investigación se haya reducido a detectar cauces de influjos y a caracterizar tradiciones, determinadas por la presencia o ausencia de tales elementos.

Consecuencia de esta concepción de la arqueología es la preocupación casi obsesiva por construir periodizaciones (Camino, 1992, 1995a, 1999), que parecen convertirse así en el objetivo final de la in-

T. P., 58, n. ${ }^{\circ} 2,2001$ 


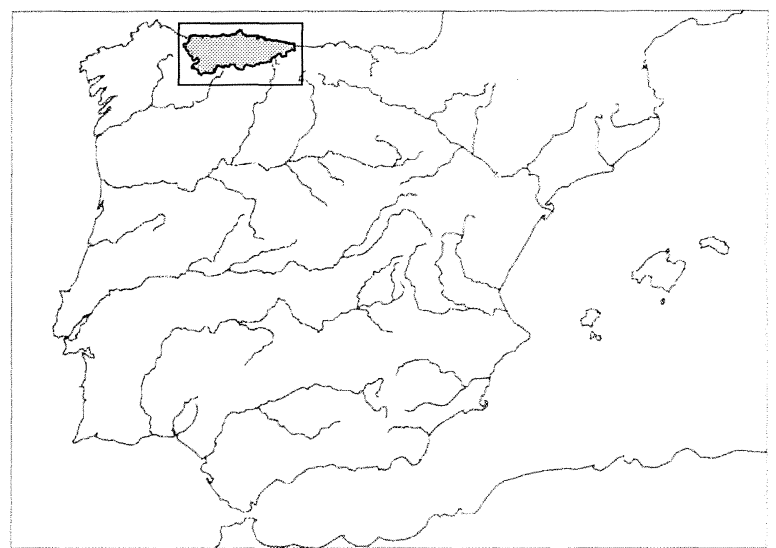

Fig. 1. Asturias, situación general en la Península Ibérica.

vestigación. El esquema general procede de la más tradicional arqueología centroeuropea, estrictamente positivista, que fue adaptado a la Península Ibérica y cuyas sucesivas reformulaciones siguen introduciendo confusión en el cada vez más abundante registro arqueológico. La situación se agrava cuando se pretende extrapolar las fases advertidas en la ocupación de dos o tres yacimientos al conjunto de la región. Por el contrario, no han recibido una atención equiparable aspectos básicos para la obtención de información histórica a partir de la arqueología, como son los análisis micro y macro espaciales, las inferencias sociológicas extraídas del registro arqueográfico, la reinterpretación y valoración de las informaciones literarias y epigráficas a la luz de la realidad exhumada en los yacimientos, etc... Da la impresión en muchos casos de que la arqueología no ha dejado de ser simple adorno o ilustración de una disciplina de alcance superior, cual sería una HistoriaAntigua consistente en continuas paráfrasis de los geógrafos e historiadores grecolatinos. En el fondo, el esfuerzo parece estar presidido por el afán de dotar de "identidad" arqueológica a los fantasmales etnónimos de laAntigüedad romana, en pos de espejismos inasequibles, como son los galaicos, astures y cántabros. Como ilustración de hasta qué punto el valor patrimonial de un castro puede depender de esta concepción, nos referiremos al Castiellu de Llagú, yacimiento arqueológico cuya importancia se ha fundamentado en los debates periodísticos en la posibilidad de su cronología prerromana, suponiéndose tácitamente que la ocupación romana posterior carecía de todo valor patrimonial que justificara su preservación.

En consecuencia, el planteamiento de este trabajo pretende establecer un balance crítico de certidumbres - escasas-y problemas -abundantessobre los yacimientos arqueológicos conocidos como castros, en el territorio del Principado de Asturias.

\section{EL REGISTRO CRONOESTRATIGRÁFICO DE LA EDAD DEL HIERRO (2)}

\subsection{Poblados con ocupación anterior a la con- quista romana}

Hasta la fecha, en Asturias se dispone de excavaciones arqueológicas modernas publicadas sobre los siguientes yacimientos: San Chuis, Castelón de Coaña, Campa Torres, Castiellu de Camoca, El Campón, Castiellu de Moriyón, Chao Samartín y Castiellu de Llagú (Fig. 2). De éstos, sólo San Chuis, Chao Samartín, Llagú y la Campa Torres han sido objeto de excavaciones extensivas. Los trabajos recientes en Coaña se centraron en solucionar los problemas, fundamentalmente cronológicos, que presentaban las estructuras exhumadas de antiguo. Los tres castros de Villaviciosa, Camoca, Campón y Moriyón carecían de excavaciones previas. Las intervenciones realizadas en ellos estuvieron orientadas al establecimiento de la secuencia cronoestratigráfica de su ocupación. Por último, se practicaron intervenciones puntuales en castros de la cuenca del Navia (La Escrita, Pendia, San Isidro, Pico da Mina). El Castillo de San Martín de Soto del Barco, situado en la desembocadura del Nalón, fue excavado sistemáticamente. Los resultados de esta última intervención permanecen inéditos, así como las campañas llevadas a cabo en 1995 y 1996 en el Castiellu de Llagú.

Las cronologías aportadas por estas actividades son diversas. Los castros del Navia se han revelado, fundamentalmente, de cronología plenamente romana. Niveles prerromanos han sido documentados en la Campa Torres, Chao Samartín, Castiellu de Llagú y los yacimientos de la Ría de Villaviciosa. En el caso de San Chuis, la existencia de niveles anteriores a la romanización no ha sido aceptada unánimemente. Es de reseñar que la información publicada sobre este último yacimiento es muy escasa, especialmente si la comparamos con el volumen de la excavación efectuada. Como ya hemos

(2) Las dataciones de C14 y su calibración han sido extraídas de la bibliografía, pero se presentan de una manera formalmente ordenada tratando de respetar la información original en lo posible. 


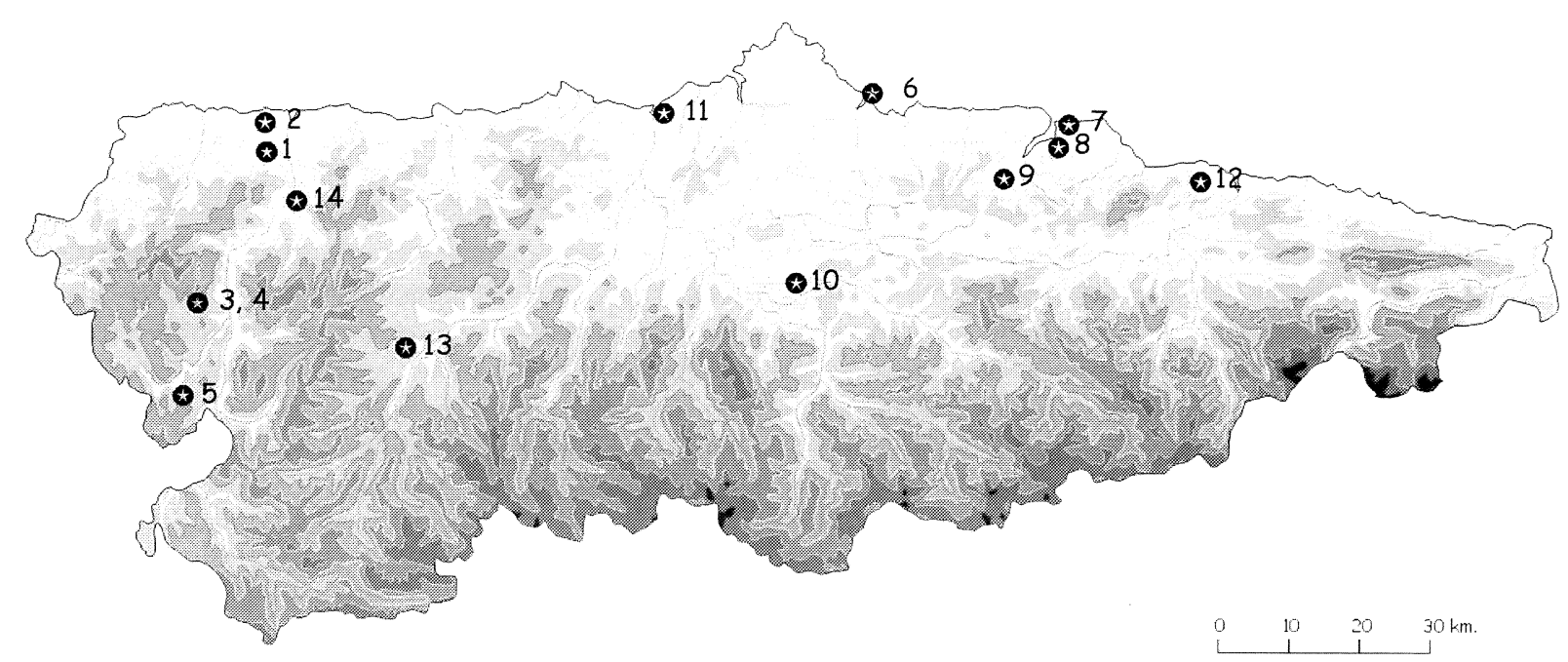

Fig. 2. Principales asentamientos castreños citados en el texto. 1: Coaña. 2: Mohías. 3. San Isidro. 4. Pico da Mina. 5: Chao Samartín. 6: La Campa Torres. 7: El Campón. 8: Miravalles. 9: Camoca. 10: Llagu. 11. San Martín. 12: Caravia. 13: San Chuis. 14. Pendia.

señalado, para ningún castro asturiano se dispone por el momento de memorias completas de excavación publicadas, sino sólo de simples avances que, en ocasiones, matizan o corrigen las interpretaciones vertidas hasta el momento, conforme el progreso de las excavaciones.

\section{Campa Torres (Cabo Torres, Gijón)}

Excavado sistemáticamente desde 1982 a la actualidad, los principales acontecimientos cronoestratigráficos registrados por los excavadores en el entorno de la muralla, desde su origen hasta el abandono del poblado, son los siguientes (Cuesta et alii, 1996: 237-245; Maya y Cuesta, 1995: 112-113; 1996: 61-63; 1999: 125-135):

1. Nivel de incendio (siglo XI a.C.). Para este estrato se poseen dos fechas de C. 14:

- GrN 18059: $2885 \pm 19$ B.P. Calibración: 1119-996AC.

- GrN 10060: 2885 + 35 B.P. Calibración: 1119-996 AC.

2. Construcción de la muralla "a veces sobre la roca viva y a veces apoyándose sobre una amplia banqueta fundacional".

3. Primera ocupación. Se poseen seis fechas radiocarbónicas, obtenidas de los niveles inferiores de los sectores XII (nivel V inf), XV (VII sup e inf), XVIII (VII) y XVIII/XIX (VII):

- UBAR 321: $2460 \pm 50$ B.P. Calibración: 764409 AC.

- UBAR 507: $2555 \pm 45$ B.P. Calibración: 739$528 \mathrm{AC}$.
- UBAR 508: $2445 \pm 40$ B.P. Calibración: 598404 AC.

- UBAR 509: 2535+45 B.P. Calibración: 802517 AC.

- UBAR 514: 2490+40 B.P. Calibración: 781476 AC.

- UBAR 518: 2480+40 B.P. Calibración: 769473 AC.

4. Segunda fase de ocupación, caracterizada por la construcción del paso de ronda y varias viviendas circulares, cuyo espacio se define por agujeros de postes y perímetros de piedra, con hogares. Se sitúan en las inmediaciones de la muralla, localizándose en los sectores VIII, XIV, XIV/XVIII, XVI. Del estrato V del sector XX, en su parte superior, identificado como nivel ocupacional de una de estas cabañas, proviene la siguiente datación:

- UBAR 371: 2250+50 B.P. Calibración: 393192 AC.

5. Tercera fase de ocupación. Corresponde al nivel IV del sector XX, al nivel III del sector XVIII y al nivel IIa del sector XVIc. Se fecha a partir "de fines del siglo II y I antes de la Era, perdurando hasta la romanización". Materiales asociados: crisoles, toberas, escorias de fundición, kernoi, cerámicas de retícula bruñida, Campaniense A tardía, cerámicas de imitaciones de clavos, fíbulas de torrecilla, hebilla anular en omega, fíbula de LaTène en hierro con pie adosado al puente, enganche de tahalí... Se obtuvieron las siguientes fechas de C14 (sector XIX, estrato III; sector XVIII, estrato III; sector XVIC, estrato IIA): 
- UBAR 372: 1870+310 B.P. Calibración: 540 AC.-780 DC.

- UBAR 373: $2060 \pm 50$ B.P. Calibración: 181 AC-56 DC.

- UBAR 382: 2080+50 B.P. Calibración: 199 AC-28 DC.

6. Fase romana. "Se abandona la habitación en la zona (...) las murallas debían mantenerse en pie, más o menos arruinadas, al menos en los siglos IV y V d.C. (...). Finalmente aparece un potente nivel de derrumbe de la muralla, de fechación imprecisa, pero en todo caso posterior al IV d.C., que marca el definitivo abandono del poblado, el cual en realidad ya debía estar semiabandonado o ruinoso desde finales del III d.C." (Maya y Cuesta, 1995a: 113).

Esta secuencia de ocupación, construida mediante la combinación de datos estratigráficos, registro material y fechas radiocarbónicas, no está exenta de dificultades, algunas de las cuales ya han sido expuestas con detalle (Ríos y García de Castro, 1998: 76-78). A continuación, reseñamos los problemas interpretativos generales que a nuestro juicio encierran algunas de las fases definidas por los excavadores:

- No han podido identificarse estructuras de habitación ligadas a la construcción de la muralla. Ello requiere una explicación arqueográfica que determine si ha habido procesos de arrasamiento de unas hipotéticas viviendas correspondientes a este periodo, o que justifique la inexistencia de las mismas.

- Las primeras fechas radiocarbónicas provienen de los niveles basales de los sectores arriba indicados. Ninguna de ellas se vincula a contextos habitacionales. En las publicaciones que han ido dando a conocer esta serie de fechas no se ha efectuado una correlación sistemática de los depósitos sedimentarios de los que fueron extraídas las muestras. Sería deseable una tabla de relación estratigráfica válida y comprensiva de la totalidad de los sectores excavados en el yacimiento que presentan vínculo con la muralla, en la que se expongan las equivalencias entre las secuencias y los hitos que generan las rupturas o diferencias.

- Propiamente, la ocupación atestiguada con estructuras de habitación corresponde a la segunda fase, que fechan entre los siglos IV y III a.C. Esta ocupación se manifiesta en varias cabañas de planta circular, asentadas bien sobre roca o sobre paquetes de nivelación. Ninguna de ellas ha sido excavada en su integridad, por lo que no podemos conocer de modo completo una sola unidad de habitación, con los problemas que de ello se derivan para la correcta interpretación espacial. Los perfiles estratigráficos publicados y comentados (Maya y Cuesta, 1995a: 110-111, sector XII-XIX, estrato III; 1999: 126, fig. 1 , sector XIV, estrato V) incorporan asimismo hogares inconexos respecto a cualquier estructura $\mathrm{u}$ horizonte de ocupación. La representación gráfica lógica debiera diferenciar con plena claridad las interfaces que suponen los hogares y suelos de ocupación a ellos vinculados, tanto de las capas de relleno y nivelación subyacentes, como de la sedimentación posterior, resultante del uso y abandono de dichas interfaces. Asimismo, las fechas obtenidas de esta sedimentación posterior han de referirse siempre al último momento de ocupación de la estructura en cuestión.

- Cuestión íntimamente relacionada con la precedente es la de la calificación comofase de ocupación de unos 200 años de unas estructuras de habitación muy párcialmente registradas en extensión, lo que impide evaluar tanto la entidad espacial de la ocupación como su diacronía. En nuestra opinión, para poder hablar de una ocupación continuada a lo largo de un período tan largo de tiempo -unas siete generaciones-habría que contar con secuencias mucho más complejas, que reflejaran tanto la utilización como la destrucción y reconstrucción de las sucesivas viviendas. En este sentido, al tratarse de habitaciones levantadas con materiales perecederos (Maya, 1999: 962-965), muy débiles, y destinadas a continuas reparaciones y demoliciones, habría que suponer potentes depósitos sedimentarios, que atestiguasen acerca de tal evolución.

- Respecto a la tercera de las fases de ocupación, que viene definida en buena parte de los sectores del yacimiento por el denominado "primer nivel de cenizas", ofrece restos de viviendas con hogares, que se disponen sobre estratos de nivelación que sellan las ocupaciones precedentes. Tampoco en esta fase se cuenta con unidades de habitación completamente excavadas, ni la documentación gráfica aportada en las publicaciones existentes refleja su existencia. Dadas las cronologías presentadas $-\mathrm{y}$ salvando los problemas que ofrece UBAR 372-, no cabe sino suponer un hiato potente con la fase precedente, fechada por UBAR 371.

Concluimos a partir de este análisis que en la Campa Torres se precisa una definición más exacta de los niveles prerromanos de ocupación, sobre todo en la etapa inicial, así como la obtención de datos que colmen los hiatos existentes entre las tres 
fases definidas por el momento por los excavadores. Nos reafirmamos por ello en nuestra apreciación anterior (Ríos y García de Castro, 1998: 78), sobre la existencia de tales hiatos.

\section{Castiellu de Camoca (Villaviciosa)}

En el Castiellu de Camoca se ha definido una única fase de ocupación que se asigna a la"Edad del Hierro Inicial" (Camino Mayor, 1995a: 122). Corresponde a un asentamiento defendido por taludes y una muralla, en el que se ha excavado una cabaña de planta oval delimitada por paredes de ramaje y barro. En palabras del autor: "la disección del talud (se refiere al talud que rodea el interior del poblado) reafirmó su elevación a base de diversos rellenos, de los que uno de piedras muy masivo adquiere el perfil de parapeto que ya se conocía en otro sector del castro. La sorpresa, aquí, fue comprobar que en su cara interna se acostaron dos capas que prosiguen bajo el nivel de ocupación excavado, deparando una de ellas hallazgos materiales. Sobre ambas y, de este modo, por encima del parapeto, se levantó una muralla de tosco paramento interno y un relleno intermedio de ripio, que debía de alcanzar una anchura próxima a los cuatro metros. Sin embargo, el paramento externo y la casi totalidad del relleno han desaparecido bajo los efectos de la erosión de ladera. Queda, por ello, pendiente la determinación de ocupaciones más antiguas que la actualmente documentada, si es que no obedecen a etapas sucesivas inherentes a la construcción del talud" (Camino Mayor, 1995a: 119-120).

De esta descripción, se deduce la siguiente secuencia estratigráfica:

1. Construcción del talud

2. Horizonte de ocupación

3. Construcción de la muralla

4. Horizonte de ocupación (concretamente, el definido durante la excavación), para el que se propusieron "fechas del siglo IV o acaso V a.C." (Camino Mayor, 1995a: 125).

Posteriormente, una nueva campaña, llevada a cabo en 1995, permitió al excavador matizar la anterior secuencia, distinguiendo, al parecer, tres sucesivos niveles de ocupación:

1. Dos cabañas. Relleno.

3. Cabaña de planta oval elíptica.

4. Muralla y cabaña de planta oval.

Para este castro se dispone de las siguientes fechas:

- CSIC, 850 (carbones dispersos): $2190 \pm 50$ BP.

T. P., 58, n. $^{\circ} 2,2001$
- CSIC, 1152 (cabaña 4): $2575 \pm 34$ B.P. Calibración: 780-410AC.

- CSIC, 1153 (cenizales): $2538 \pm 26$ B.P. Calibración: 800-540AC.

- CSIC, 1154 (cabaña 3): $2449 \pm 45$ B.P. Calibración: 770-400AC.

La disparidad entre la primera de las fechas y las otras tres inclinó al excavador a descartarla, "debiendo residir su anómala modernidad, hoy sobradamente desmentida por el repertorio arqueológico, en deficiencias de muestreo" (Camino, 1999: 156).

\section{El Campón (Villaviciosa)}

Una gran trinchera de $35 \mathrm{~m}$ de longitud ha permitido definir una única fase de ocupación, caracterizada por una muralla, el talud y foso correspondiente y una posible cabaña de material perecedero muy cercana al paramento de la muralla (Camino Mayor, 1999: 154-156).

Lás dos fechas radiocarbónicas obtenidas son las siguientes:

- UtC 7035 (ocupación interior): $2461+31$ B.P. Calibración: 758-418AC.

- UtC 6954 (relleno de muralla): $2508 \pm 40$ B.P. Calibración: 777-530AC.

\section{Castiellu de Moriyón (Villaviciosa)}

Camino Mayor (1995a: 117-119, 124-126; 1996; 1999: 159-160) ha establecido tres fases de ocupación:

1. Nivel de ocupación anterior a la muralla. Las cerámicas coinciden en buena parte con las documentadas en el Castiellu de Camoca. Las fechas radiocarbónicas publicadas de esta fase son las siguientes:

- CSIC 849 (procedencia: bajo muralla): 1900 \pm 60 B.P. Calibración: 1-250AD.

- CSIC 875 (procedencia: bajo muralla): 2320 \pm 45 B.P. Calibración: 410-240 AC.

2. Construcción de la muralla y ocupación de todo el asentamiento. Fueron documentadas en esta fase cabañas con zócalo de piedra y paredes de entramado de madera y barro, de planta oval, con "hogar centrado pero próximo a la pared meridional". Las fechas radiocarbónicas adscritas a esta fase son las siguientes:

- CSIC 874 (procedencia: muralla): $2200 \pm 50$ B.P. Calibración: 390-100 AC.

- CSIC 873 (procedencia: derrumbe muralla): $2280 \pm 50$ B.P. Calibración: 400-190 AC.

- CSIC 876 (procedencia: vigas de la construc- 
ción 2): $2100 \pm 60$ B.P. Calibración: 210 AC.$30 \mathrm{AD}$.

- CSIC 1025 (procedencia: construcción 3a): $2010 \pm 25$ B.P. Calibración: 50 BC.-70 AD.

- CSIC 1004 (procedencia: construcción 5): $1820 \pm 25$ B.P. Calibración: 130-250 AD.

3. Ocupación tras el derrumbe de la muralla. Se trata "de diversos niveles y construcciones que tienen en común su asociación con síntomas inequívocos de descuido de la muralla" (Camino Mayor, 1995a: 119). Los materiales más significativos son romanos (TSH, imitación de barniz rojo pompeyano, hebillas anulares, etc, ...).

- CSIC 1024 (procedencia: construcción 3b): $2060 \pm 25$ B.P. Calibración: 120 BC. -10 AD.

En el trabajo de 1999, Camino pretende determinar la cronología de la muralla a partir un test de similaridad estadística que afecta a las fechas CSIC 874,876 y 873 , concluyendo que "el balance de esta operación fue $2203 \pm 30$ B.P., cal AC.: 380-180" (Camino, 1999: 160).

A la luz de estos datos proporcionados por el excavador, se imponen las siguientes consideraciones:

- La primera fase se fecha con dos muestras divergentes entre sí casi 400 años, lo que arroja la forzosa necesidad de excluir una de las dos, o ambas.

- La segunda fase dispone de dos fechas contradictorias para la muralla. Según la relación ofrecida, el derrumbe sería anterior a la muralla, lo cual, en principio, parece imposible. Esta situación ha sido explicada con posterioridad a la primera publicación de las fechas, suponiendo que " ¿acaso no será probable que se trate de un material incorporado al relleno de la muralla y cuyo proceso de derrumbe comportó algo muy similar a las célebres inversiones estratigráficas?" (Camino, 1999: 160). A nuestro juicio, y sin cuestionar la validez de esta explicación, esta deducción estratigráfica habría debido señalarse en el momento de la presentación pública de las fechaciones, y no como respuesta a una crítica posterior (Cuestaetalii, 1996: 246-247). Por otro lado, las cabañas pertenecen a un horizonte cronológico muy posterior a la erección de la muralla. Por ello, el registro material recuperado en estas estructuras de habitación debe relacionarse estrictamente con la fecha obtenida para ellas y no con el momento de construcción de la cerca.

- La fase de ocupación romana se revela anterior, a la luz de los datos geocronológicos, a la cabaña 5 de la segunda fase. Incluso, la cabaña $3 b$ es radiocarbónicamente anterior a 3a, lo que estratigráficamente es imposible.

- Por todo ello concluimos que las cronologías absolutas y relativas del Castiellu de Moriyón precisan aclaraciones y correcciones imprescindibles para su correcta valoración histórica.

\section{Castro de San Chuis (Allande)}

Para este castro, Maya (1988: 60) propuso una secuencia estratigráfica que dejaba abierta la posibilidad de la existencia de un nivel prerromano, hipótesis que fue confirmada por Jordá Pardo (1990: 124-125), basándose en un estudio de los materiales del castro (Manzano Hernández, 1986-87). Recientemente, esta propuesta ha sido reafirmada en al menos dos trabajos, en los que se publican fechas radiocarbónicas obtenidas a partir de los materiales recuperados de las excavaciones dirigidas en los años 80 por Jordá Cerdá (Cuesta, Jordá, Maya y Mestres, 1996; Jordá Pardo y García Martínez, 1999). Las datáciones y contextos de las mismas son las siguientes (fig. 3):

- UBAR 351 (Procedencia: nivelVI, interior de habitación en C-21): $2600 \pm 60$ B.P. Calibración: 795 AC.

- UBAR 218 (Procedencia: nivel VI, exterior, cuadro B-7): $2360 \pm 60$ B.P. Calibración: 400 AC.

- UBAR 350 (Procedencia: nivel IV, interior de habitación en C-21): $2150 \pm 60$ B.P. Calibración: $185 \mathrm{AC}$.

- UBAR 216 (Procedencia: nivel IIIB, interior de cabaña en D-5): $2050 \pm 50$ B.P. Calibración: 39 AC.

- UBAR 217 (Procedencià: nivel II, exterior, cuadro B-7): $1800 \pm 140$ B.P. Calibración: 240 AC.

De estas fechas, los actuales estudiosos del castro han sostenido una ocupación "que podría iniciarse entre finales del siglo IX y los albores del siglo VIII a.C., pero siempre como mínimo en el sigloVI y continúa hasta la ocupación romana, con momentos fechados entre mediados de los siglosVI a IV a.C. y los siglos I a.C./d.C.” (Jordá y García, 1999: 145).

$\mathrm{Al}$ margen de las críticas que esta interpretación ha despertado (Camino, 2000: 10), por nuestra parte apuntamos lo siguiente:

- En primer lugar hay que señalar que los responsables directos de la excavación y firmantes de los primeros y únicos informes publicados nunca barajaron la posibilidad de una ocupación tempo- 


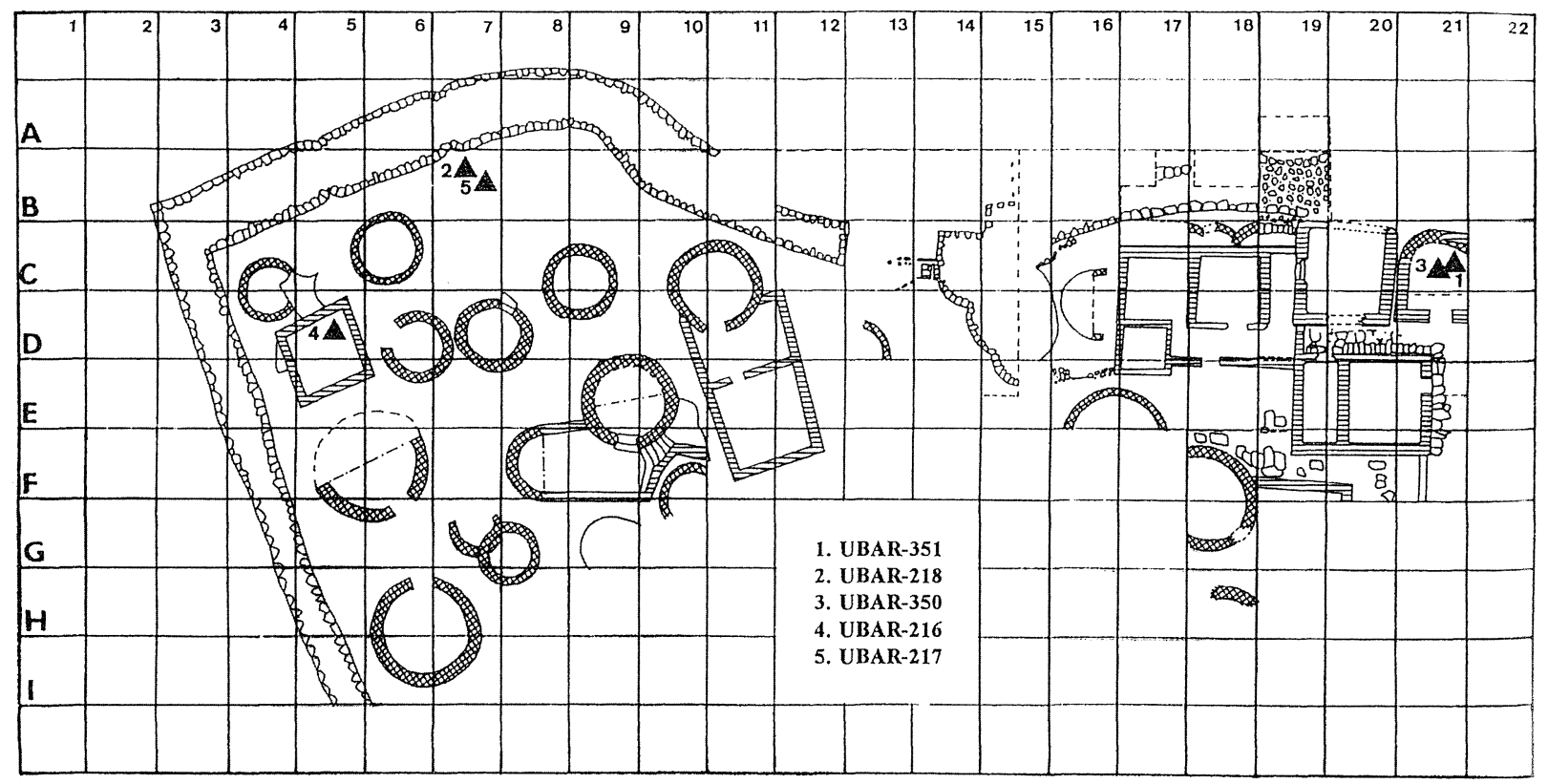

Fig. 3. Castro de San Chuis. Planta general del área excavada, con indicación del lugar de extracción de las muestras radiocarbónicas (según Cuesta et alii, 1996: 229).

ral tan antigua (Jordá Cerdá, 1985, 1987, 1990; Jorda et alii, 1989). Los materiales recuperados y publicados hasta el momento no han dado pie a suponer un inicio de la ocupación del yacimiento en el Bronce Final. Tampoco se describe una estratificación que integre depósitos sedimentarios y estructuras que pueda ser comprensiva de más de míl años de ocupación. De hecho, las columnas estratigráficas publicadas en estos últimos trabajos (Fig. 4), que sirven para proporcionar un contexto arqueográfico a las cinco muestras radiocarbónicas (Cuesta et alii, 1996: 231, fig. 4; 234, fig 5; reproducción en Jordá y García, 1999: 139-140), describen sólo tres fases de ocupación: el nivel II, tardorromano, los niveles IV y V, romanos, y el nivelVI, en el que se obtuvo la muestra más antigua (UBAR 351). Estas secuencias no integran las estructuras exhumadas con los depósitos sedimentarios relacionados con las mismas, carencia especialmente grave si se tiene en cuenta la amplitud de la superficie excavada en este castro, con múltiples unidades de habitación puestas al descubierto totalmente, en las que se aprecian superposiciones y refacciones, de las cuales habría de deducirse arqueológicamente la historia de la ocupación del poblado.

- Aún admitiendo la validez de estas columnas, de este registro se deduce exclusivamente que el yacimiento tuvo una ocupación puntual en un momento vinculado al Bronce Final, tras lo cual suce- dió un largo periodo de abandono, hasta la ocupación romana, a la que pertenece la mayor parte del yacimiento visible hoy en día. Ahora bien, en el estado actual de información no son admisibles ni las columnas como tales ni las inferencias históricas que se derivan de ellas. En primer lugar, los autores asimilan el nivel en el que fue tomada la muestra UBAR 218, definido como un vertedero situado en las proximidades de la muralla, al nivel VI en el que fue tomada la muestra UBAR 351, correspondiente en principio a un fondo de cabaña. Es estratigráficamente inverosímil que las sedimentaciones exterior e interior ligadas a la ocupación de una unidad de habitación sean coincidentes, por lo que en principio esta asimilación no es aceptable, máxime si tenemos en cuenta la separación -superior a $50 \mathrm{~m}$ - existente entre los puntos en los que fueron recogidas las muestras (Fig. 3). La distancia cronológica existente entre ambas fechas, casi 400 años, invalida toda posibilidad de coetaneidad y, por tanto, reafirma su adscripción a unidades estratigráficas independientes.

- Resulta incomprensible que el contexto estratigráfico de la muestra UBAR 218 no haya sido plena y definitivamente establecido en el momento de la excavación de la unidad estratigráfica de la que proviene. Las posibilidades hipotéticas que se defienden (Cuesta et alii, 1996: 232-233) responden a un ejercicio de reubicación teórica a posterioride 
un registro arqueológico falto de contexto y que, por tanto, ofrece dificultades para su correcta interpretación.

Pasando al análisis monográfico de las muestras, relacionándolo con el registro obtenido en la excavación, cabe anotar lo siguiente.

- La muestra UBAR 351 procede del interior de una cabaña de planta circular, con muros de mampostería cimentados en roca, y ha sido extraída de un nivel que adosa çontra éstos. Por ello, proporciona un terminus ante quem para la fundación de esta cabaña. Los dos niveles inmediatamente superiores se remiten a la ocupación romana, distante al menos 600 ó 700 años de esta primera fase. Se da la circunstancia que esta ocupación romana es "la responsable de la construcción de unos muros rectilíneos que se cimientan sobre los anteriores curvos" (Cuesta et alii, 1996: 231). Sin embargo, páginas después, se sostiene que dichos muros rectilíneos configuran una estructura rectangular que "descansa sobre la estructura circular antigua aprovechando parte de los muros de la anterior, de forma que una de sus esquinas presenta una marcada curvatura frente a la otra visible que es angular" (Cuesta et alii, 1996: 233). Por lo tanto, no sabemos si la cabaña de la fase romana anula o reforma la vieja estructura prerromana. Asimismo, queda en suspenso la relación entre los niveles IV y V, definidos como suelo de ocupación y nivel de drenaje respectivamente, y la última estructura romana. No se explica tampoco el importante hiato existente entre las fases prerromana y romana. En este sentido, resulta de difícil comprensión que la limpieza llevada a cabo por los ocupantes romanos, sugerida para explicar la inmediata superposición de niveles romanos a estratos prerromanos tan antiguos, no haya incluido el arrasamiento de muros. Por el contrario, si estos muros fueron utilizados como superficie de cimentación, huelga la limpieza, pues el proceso habitual y lógico consiste en el aporte de rellenos para conformar plataformas estables niveladas, aprovechando la cimentación preexistente.

- La UBAR 350 se relaciona con la fase de ocupación romana señalada anteriormente (nivel IV). Los materiales asignados a ese nivel se fechan en el siglo I d.C., lo que supone un considerable desfase entre ambas cronologías. Este desfase ha sido explicado por los investigadores de la siguiente forma: "hemos fechado un momento durante la ocupación indígena en que un árbol fue cortado,

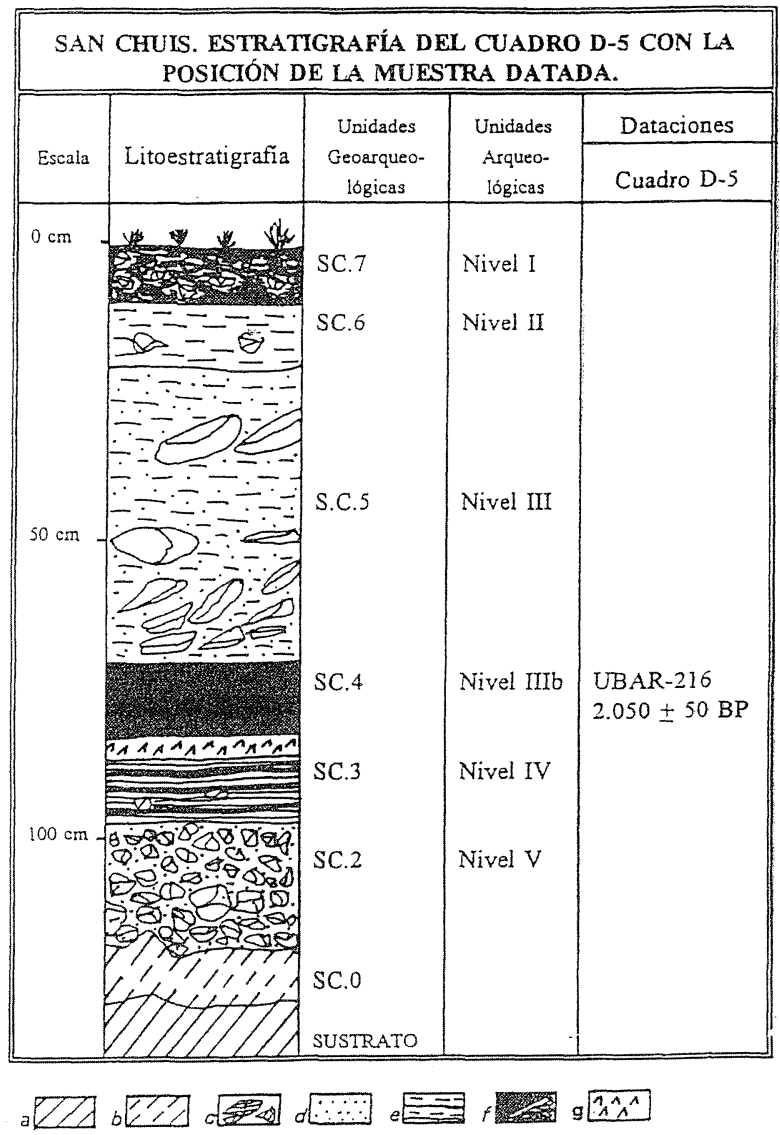

Fig. 4. Castro de San Chuis. Columna estratigráfica del cuadro D-5 (según Cuesta et alii, 1996: 270).

siendo sometido a una utilización durante al menos un siglo, para ser carbonizado en época romana" (Cuesta et alii, 1996: 234). Tal explicación implica una petición de principio: ¿cuál es la fase prerromana definida arqueológicamente de la que pueda provenir el material en cuestión? No discutimos la fecha en sí sino su significado histórico.

- Idéntico razonamiento se impone respecto a la UBAR 216, donde también la discordancia entre materiales arqueológicos y fecha radiocarbónica es evidente, pues la muestra procede del nivel IIIb, identificado como un incendio de techumbre de una unidad de habitación perteneciente a la ocupación romana. Nuevamente ha sido puesta en relación con el reaprovechamiento por parte de los ocupantes romanos de maderas procedentes de una fase anterior, para la que ningún dato objetivo se proporciona.

- Finalmente, sólo la UBAR 217 parece corresponder armónicamente al registro arqueológico, al atestiguar un momento de habitación en torno al 
siglo III d.C., que había sido previamente definido a partir de los materiales cerámicos.

\section{Chao Samartín (Grandas de Salime)}

Los resultados publicados hasta el momento de las excavaciones y sondeos arqueológicos realizados en yacimientos del valle del Navia (Carrocera Fernández, 1987a, 1987b, 1992, 1994) han establecido el momento fundacional de los poblados estudiados (Coaña, La Escrita, Pendia, San Isidro, Picu da Mina) en el siglo I d.C.

La publicación en los últimos tiempos de informes sobre las excavaciones llevadas a cabo en el castro de Chao Samartín ha permitido incorporar un horizonte prerromano al poblamiento castreño del sector occidental deAsturias (Villa Valdés, 1998a; 1998b; 1999a y 1999b). No obstante, de lo publicado hasta el momento, se desprende que este horizonte, lejos de estar definido como una ocupación única, estaría compuesto por los siguientes hitos cronoestratigráficos:

1. Un primer recinto en el área más elevada del yacimiento, definido por una empalizada junto al acantilado que cierra el poblado por el Oeste, y por una línea de muralla precedida de un foso de $7 \mathrm{~m}$ de anchura al Este. Se asocia a esta fase una habitación que se compone de una planta de tendencia rectangular y esquinas redondeadas. El registro se caracteriza por la total ausencia de materiales romanos (Villa, 1999a:116-118). La empalizada, al decir de su excavador, ha sido reconstruida como "una robusta estructura de madera, con puntos de apoyo pareados dispuestos a cada 5-5,50 m. Los hoyos de postes, de dimensiones comprendidas entre los 0,16 y $0,50 \mathrm{~m}^{2}$, conservan las cuñas de madera introducidas para fijar los pies del armazón". Al exterior, una tercera línea de apoyos constituida por asientos de piedra que determinan junto con los anteriores una superficie cuadrangular, parece sugerir el remate en torre de la empalizada" (villa, 1999a: 116). Esta última estructura estaría destinada a proporcionar "un óptimo control visual sobre el itinerario de acceso al recinto y su entorno próximo" (Villa, 1999a). A esta reconstrucción se oponen a nuestro juicio los siguientes datos:

- En principio la situación topográfica de esta estructura no parece estar en consonancia con una estrategia defensiva. Se localiza en la zona de la máxima cota del asentamiento, próxima y paralela a un acantilado sumamente escarpado de cerca de trescientos metros de desnivel, con una reducida de quinientos metros desde el cauce del río Cabalos.
Creemos que esta circunstancia hace innecesaria la construcción de una empalizada.

- No conocemos los argumentos que permiten vincular como partes de un mismo proyecto constructivo esta estructura de material perecedero con la línea de muralla y el foso localizado en el sector oriental de este recinto. Para este último su amortización por rellenos y estructuras constructivas de la fase de ocupación romana marca una cronología relativa.

2. Foso exterior, anulado por la muralla del recinto principal (Villa, 1999a: 119).

3. Muralla del recinto principal, construida según el sísterna de módulos asociados.A ella se vinculan al menos seis unidades de habitación, de plantas circulares o rectangulares con esquinas redondeadas, con obra de mampostería y dotadas de pavimentos de tierra apisonada. Disponen de hogares sobre plataformas de cuarcita, con receptáculos auxiliares (Villa, 1999a: 119-121).

Se cuenta para esta fase con una fecha radiocarbónica:

- CSIC 1158: 2160 +24 B.P. Calibración: 350$110 \mathrm{AC}$.

Para la misma se asignan dos procedencias; en un lugar, se señala que fue recogida "de niveles asociados al paramento interno de la muralla, elevada sobre el primitivo foso" (Villa, 1999a: 120); y en otro, de carbones obtenidos "en el interior de un pequeño horno para fundición de cobre nativo localizado en el espacio comprendido entre las construcciones C-1, C-9 y la muralla" (Villa, 1998a: 990). Permanece por aclarar la relación del horno aludido con los niveles vinculados a la muralla y las características de esta relación.

El paramento externo de dicha muralla de módulos aparece en conexión con una serie de depósitos y horizontes de ocupación, cuya excavación ha permitido elaborar a su excavador una secuencia de cronología relativa que engloba tres horizontes de uso (niveles XI, VIII y III), que se intercalan con sucesivos niveles de derrumbe (X, VII y II) y los rellenos de trincheras de fundación que documentarían sucesivas refacciones y reconstrucciones del paramento (niveles VI, V y IV). Toda esta secuencia se inscribe en cronologías anteriores a la ocupación romana, puesto que la muralla "una vez perdido definitivamente su carácter defensivo, fue utilizada como elemento de contención y aterrazamiento del núcleo urbano" (Villa, 1999a: 118-119, lám. 6).

En principio, y sin que se rechace la documentación ofrecida, existen puntos que precisan una

T. P., 58, n. $^{\circ} 2,2001$ 
aclaración. En primer lugar, la interpretación como foso del surco del substrato que subyace a la mura1la. Tanto sus dimensiones -apenas 1,50 m de anchura y menos de $1 \mathrm{~m}$ de profundidad- como la disimetría de su perfil, no parecen corresponder a un foso defensivo, tal y como en el mismo poblado han sido convincentemente identificados. En segundo lugar, el módulo de las lajas que supuestamente configurarían los paramentos derrumbados ofrece un grosor muy inadecuado a una fábrica defensiva, por su espesor medio que no parece alcanzar los $5 \mathrm{~cm}$. A ello se une el tipo de material, finas lajas tabulares de pizarra, que contrastan con la mampostería cuarcítica que predomina en la fábrica conservada de la muralla. En cualquier caso, la estratigrafía referida sólo ilustra acerca de la historia constructiva del módulo afectado, nunca sobre la totalidad del trazado del cerco defensivo.

\section{Castiellu de Llagú (Oviedo)}

Las dos primeras campañas de excavación se llevaron a cabo en los años 1994-1996. No han sido publicadas, por razones ajenas a la voluntad de los arqueólogos, y por el momento sólo se han avanzado los resultados de varias pruebas radiocarbónicas (Maya y Mestres, 1998). Los trabajos se centraron en el estudio de las estructuras defensivas del flanco meridional del asentamiento (Lams. I y II), poniendose al descubierto los siguientes elementos en sucesión cronoestratigráfica (3).

1. Muralla de trazado lineal continuo, elaborada con aparejo irregular de grandes bloques. Dispone de un nervio central, que puede interpretarse bien como elemento estructural de refuerzo o bien como la prueba de un aumento del grosor de la estructura en una segunda actuación constructiva. Al sur de este muro discurren dos muros de contención levantados con un aparejo de similares características al anterior.

2. Reforma de la primera fortificación, mediante la inserción de módulos o cajones rectangulares, adosados unos a otros. Se disponen sobre el aterrazamiento proporcionado por uno de los muros de contención de la fase anterior. El aparejo de los paramentos exteriores se compone de hiladas regulares de bloques cuadrangulares someramente escuadrados, con cuñas y lajas de nivelación. Paralelamente se adosó al paramento interior de la muralla

(3) La descripción que ofrecemos a continuación, así como las fotografías, se basan en el trabajo como arqueólogo en la segunda campaña de excavaciones (noviembre 1995-julio 1996) de uno de nosotros (Sergio Ríos González).

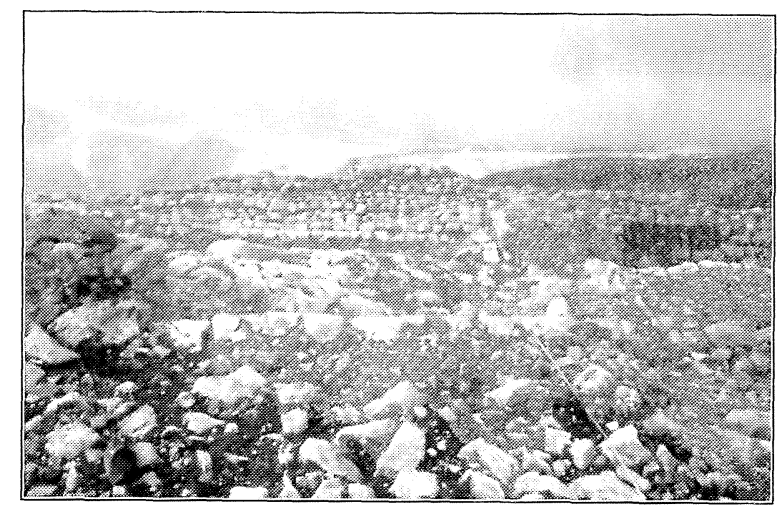

Lám. I. Castiellu de Llagú. Aparato defensivo meridional, vista desde el norte.

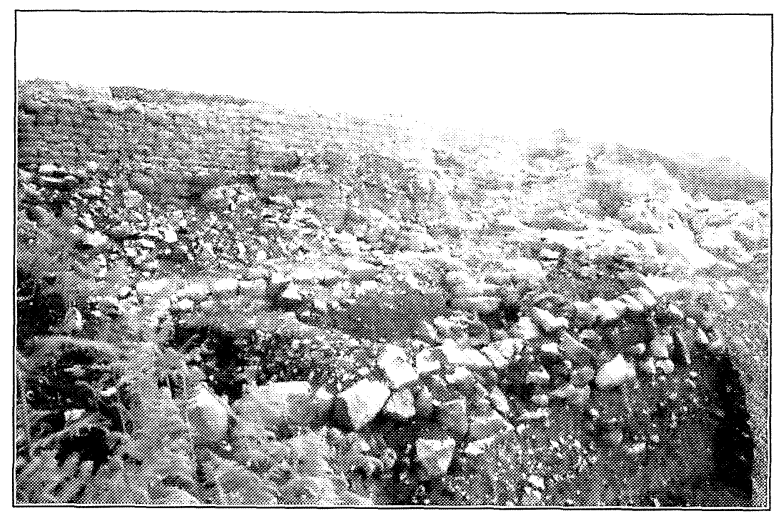

Lám. II. Castiellu de Llagú. Aparato defensivo meridional, vista desde el suroeste.

de la fase anterior un cuerpo circular turriforme, dotado de escalera perimetral, cuya interpretación como sistema de acceso al plano superior de las defensas presenta algunas dificultades, por la desproporción evidente entre obra y destino. Una función similar hubiera podido ser desarrollada con considerable ahorro de energía y recursos mediante una escalera adosada al paramento interior. El aparejo participa de las mismas características que los módulos anteriores. La escalera por el contrario ofrece sectores con sillería de módulo alargado.

3. Construcción de un gran aterrazamiento al sur de la línea de módulos anterior, contenido por muros de contención cuyo paramento exterior resultó vencido y abatido por el peso de los rellenos, habiéndose excavado éstos y permaneciendo en posición postdeposicional las hiladas de los lienzos. Ello conllevó la reforma del sistema de acceso. En primer lugar se amortiza el torreón de la fase anterior, sellándose la escalera. En segundo lugar, se construyen dos puertas. La interior corresponde al 
denominado "cuerpo de guardia" o "compartimento enlosado" (Maya y Mestres, 1998: 7-8, foto inferior). Se trata de un tramo de calzada pavimentado con losas calizas irregulares, delimitado lateralmente por dos muros que se superponen a la antigua muralla. La exterior, situada en el sector occidental, se abre entre dos módulos que enlazan con el muro de contención del aterrazamiento exterior.

Una tercera campaña tuvo lugar en el año 1998. De ésta sí se conoce un informe preliminar (López et alii, 1999: 237-251), en el cual se describe someramente el alcance de la actuación, que consistió en sondeos distribuidos en el interior y en una terraza exterior. Los resultados de ambas campañas, a tenor de los datos conocidos, son homologables en cuanto a la periodización. Se ha definido un horizonte de ocupación prerromano, al que no se vinculan estructuras de habitación.

Las fechas radiocarbónicas publicadas más significativas de las dos primeras campañas son las siguientes:

- UBAR 489: 2276 +47. Calibración: 398-201 AC.

- UBAR 490: 2308 \pm 62. Calibración: 751-185 AC.

- UBAR 493: 2380£48. Calibración: 761-369 AC.

Las dos primeras provienen, según Maya y Mestres (1998: 9) del nivelVII, sector 1, cuadrícula BE: "el estrato VII se supone el inferior y debe fechar, por tanto, los primeros momentos de ocupación del castro en esa zona". Podemos precisar que estas muestras fueron extraídas del depósito que rellenaba la trinchera de fundación de la muralla de la primera fase. Por lo tanto, no cabe duda de su cronología prerromana.

La tercera campaña ha proporcionado igualmente varias dataciones radiocarbónicas (López et alii, 1999: 244), extraídas de los niveles de ocupación prerromanos, en un caso asociados a la muralla y en otros inferiores a los zócalos de cabañas romanas. Su relación es la siguiente.

- Sector Oeste, sondeo 5: $2160 \pm 38$ B.P. Calibración: 359-63 AC.

- Sector Este, sondeo 1: $2414 \pm 41$ B.P. Calibración: 761-393 AC.

- Sector Este, sondeo 1:2355 \pm 44 B.P. Calibración: 536-252AC.

No estamos en condiciones, a tenor de la información publicada, de precisar a qué fase de las anteriormente señaladas pertenece la muralla relacionada con estas muestras. En todo caso, estas fechas corroboran la construcción prerromana del tramo afectado.

Tanto en la segunda campaña como en la tercera las cabañas definidas pertenecen en su totalidad a la fase romana del poblado. Se trata de tambores o zócalos circulares de piedra, rellenados en su interior, conformando plataformas sobre las que se erigía una estructura de material perecedero, verosímilmente entrelazados de ramaje y madera con manteado de arcilla, y cubierta cónica apoyada sobre poste central.

Restan por examinar dos yacimientos de los que se cuenta con antiguas y parciales excavaciones. El Picu del Castro de Caravia, a tenor por lo publicado por su excavador en 1919 (Llano, 1919: 31 y ss.), corresponde a un asentamiento en el que no se señalan elementos de cultura material propios del contacto con el mundo romano, aspecto éste que parece confirmarse por los resultados de un reciente sondeo (Adán et alii, 1994). Por lo demás, la información disponible es muy parca. Por último, el Picu Castiellu la Collá (Siero), del que sólo se conoce un conjunto de hallazgos realizados en el siglo XIX y depositados en el MuseoArqueológico deAsturias (Escortell y Maya, 1972), no merece ser considerado como tal yacimiento hasta la realización y publicación de nuevas excavaciones.

\subsection{El impacto de Roma sobre los poblados cas- treños de la Edad del Hierro}

Los datos arqueológicos disponibles indican que los contactos con las civilizaciones mediterráneas no se establecen de modo decisivo hasta la conquista militar, que tuvo lugar en los primeros años del Principado deAugusto (29-19 a.C.). Existen testimonios puntuales de objetos de procedencia mediterránea fechados con notable anterioridad a este acontecimiento (cerámicas áticas, campanienses e ibéricas de la Campa Torres, datadas en los siglos IV-I a.C.). Ahora bien, estos hallazgos han de interpretarse no como el testimonio de contactos directos con el foco productor, sino más bien como reflejo de intercambios comerciales a cargo de sucesivas intermediaciones.

El primer testimonio arqueológico de asentamiento romano es la lápida del Cabo Torres en honor de Augusto (9-10 d.C.), cuya fecha resulta coherente con la del primer registro material romano en asentamientos castreños, que corresponde también al periodo augústeo-tiberiano: TSI del Castie-

T. P., 58, n. ${ }^{\circ} 2,2001$ 
llu de Llagú y de la Campa Torres. En el valle del Navia, se fija la plena implantación a mediados del siglo I, aproximadamente durante el principado de Claudio (Carrocera, 1994: 218; Villa, 1999: 121).

La integración del territorio asturiano dentro de las fronteras del Imperio Romano se manifiesta a través de una serie de modificaciones apreciables en las áreas de implantación, el modelo de asentamiento, la arquitectura habitacional y defensiva, y la organización sociopolítica.

El valle del Navia es la única comarca regional en la que el fenómeno de la implantación castreñoromana cuenta con una prospección detallada que permite una aproximación al modelo de poblamiento en tiempos altoimperiales. De la autarquía y autonomía anterior a la romanización, tal y como ha sido establecida para las comarcas del Bierzo leonés (Sánchez Palencia y Fernández Posse, 1985; Fernández Posse y Sánchez Palencia, 1988; 1998; Orejas, 1996) y del valle del río Ulla (Carballo, 1990), se asiste a una transformación consistente en una jerarquización de los núcleos de poblamiento, cuyos lugares de emplazamiento dependen de decisiones que implican una organización de alcance supralocal. En el valle del Navia la clave de esta reorganización reside en la minería aurífera. Se aprecian asentamientos cuya razón de ser sólo se explica por la presencia de yacimientos mineros o instalaciones relacionadas con los mismos, fundamentalmente obras hidráulicas. Asimismo, la interdependencia de los asentamientos permite asegurar el abastecimiento de aquellos poblados cuyo entorno inmediato es claramente inadecuado para garantizar la autarquía (Carrocera, 1995).

Hasta ahora, se conocen modificaciones romanas en poblados prerromanos en tres ejemplos: el Castiellu de Llagú, Chao Samartín y la Campa Torres.

En el primero, se apreció una reforma consistente en una ampliación del recinto y un considerable incremento del aparato defensivo. Sin embargo las estructuras de habitación pertenecientes al periodo consisten, como ya se ha visto, en tambores de mampostería sobre los que se levantan paredes de entramado vegetal, semejantes en todo a las cabañas de la Edad del Hierro descritas en Moriyón, en la ría de Villaviciosa (Ríos y García de Castro, 1998: 38; López Álvarez y López, 1999: 241-242; Maya y Mestres, 1999: 11)

En el segundo, en la traza del poblado que ha llegado hasta nosotros, el responsable de las excavaciones distingue estructuras de habitación prerro- manas y romanas, situándose parte de las segundas sobre la antigua muralla exterior (Villa, 1998a: 980985; 1999a: 121). A la reforma romana atribuye "una doble línea de fosos, paralelos y contiguos, sobre el flanco oriental del yacimiento"(Villa, 1999a: 120), que identifica con un "sistema de fossa duplex" (Villa, 1999a: 121). Constituye la última fortificación del poblado y su amortización definitiva llegó a comienzos del siglo II d.C. La dinámica sedimentaria que se advirtió en la excavación de sus rellenos no es homogénea, permaneciendo sin aclarar en los avances publicados las razones de esta divergencia. Igualmente quedan sin aclarar los vínculos entre estas zanjas y la línea de muralla. Sabemos que parte de ella resultó desmontada, aprovechándose los materiales en la construcción de nuevas viviendas (Villa, 1999a: 121), parte de las cuales se disponen sobre el trazado de la citada cer$\mathrm{ca}$, a nivel del plano superior de arrasamiento. Este plano aparece definido en el interior del poblado mediante un nivel de relleno cuya relación con las estructuras de habitación exhumadas permite a su excavador adscribirlas a la fase prerromana o romana del poblado. De este modo, las estructuras dispuestas sobre el relleno serían romanas y aquellas cuyos paramentos exteriores aparecen cubiertos por él serían prerromanas (Villa, 1998a: 982-985). La prueba arqueológica de la cronología absoluta de este relleno no ha sido aportada hasta el momento. Por ello, queda en suspenso todo juicio sobre la validez de esta interpretación.

A nuestro parecer, un análisis del plano permite asegurar que la ocupación romana del poblado no constituye la materialización de un único proyecto unitario. El sector suroccidental del área excavada está ocupado por una plaza pavimentada que corta las estructuras preexistentes, en especial el edificio balneario (Ríos, 2000: 111-114). Dado que esta construcción es uno de los productos de la aculturación romana del poblado, la plaza forzosamente remite a una reforma posterior, igualmente debida a necesidades impuestas por dicha ocupación.

En el tercero, la ocupación romana, al decir de sus excavadores, arrasó los niveles y estructuras de habitación de las fases de ocupación anteriores, sustituyéndolas por un replanteo urbanístico que introduce las viviendas angulares, de varias dependencias, con muros de mampostería y argamasa, cubiertas de tégula, etc. (Maya y Cuesta, 1992: 150152; Maya, 1999: 965-968). Hay que decir que tal ocupación se asentó en la Campa interior, en un sector muy alejado del que ha suministrado hasta el 
momento los testimonios de ocupación prerromanos, ligados a la fortificación. Por el momento no se ha publicado ninguna estructura de habitación completa, pero lo visible permite asegurar la falta de vínculos de cualquier tipo con la tradición constructiva anterior, tanto en plantas como en alzados. Está por definir el carácter funcional de esta amplia superficie urbanizada, de la que hasta el momento no ha sido publicada ninguna planimetría.

\section{INTERPRETACIÓN DEL REGISTRO}

El origen de las actuales controversias en torno a la Edad del Hierro en Asturias arranca de los planteamientos sostenidos por Maya en su tesis doctoral, leída en 1975 y publicada en 1988. Este trabajo cerraba un capítulo en la historia de la investigación, al analizar y estudiar sistemáticamente el registro material conservado procedente de excavaciones antiguas en castros asturianos. En él se establecía un completo corpus arqueográfico, amén de un inventario de yacimientos, tras cuyo análisis se sostenía la existencia de una Edad del Hierro "previa a la conquista". Dicha fase define el modelo de asentamiento castreño, que perdurará en época romana, apuntándose la posibilidad de que algunos materiales, como dos fíbulas de bucle procedentes de La Escrita y un fragmento cerámico de Coaña, a los que se atribuyen cronologías en torno al siglo $\mathrm{V}$ a.C., sean testimonios de esta etapa (Maya, 1988: 296-297). En el mismo trabajo se defendía la posibilidad de que San Chuis dispusiera de una estratigrafía anterior a la ocupación romana (Maya, 1988: 59), así como se valoraban como prerromanos los hornos de fundición localizados en el interior de la Campa Torres (Maya, 1988: 20).

Esta primera interpretación fue contradicha por Carrocera (1990a), quien negó la significación cronológica de los materiales aludidos por Maya por su falta de contexto arqueológico, argumentando que "no existen claros elementos de juicio para definir la cultura castreña prerromana, y los pocos que tenemos invalidan las divisiones efectuadas hasta ahora". A la vez, afirmaba que, en aquel momento, "podemos señalar que no conocemos ningún nivel de ocupación prerromano en la totalidad del territorio de la actual Asturias, si exceptuamos por un lado el castro de Caravia (...) y por otro lado toda una serie de materiales sin contexto cultural" (Carrocera, 1990a: 129).

A partir de entonces, el debate se centró en la defensa respectiva de ambas posturas. La excavación de la Campa Torres aportó estratigrafías prerromanas (Maya y Cuesta, 1992: 148-150), que fueron puestas en entredicho por Carrocera (1994), crítica a la que respondieron a su vez Maya y Cuesta (1995a y 1996: 61-68). Paralelamente, se fueron dando a conocer avances sobre las excavaciones llevadas a cabo en castros de la ría deVillaviciosa, Moriyón y Camoca, que demostraban la realidad incuestionable de horizontes prerromanos en el centro de la región (Camino, 1992: 137, 144; 1995a: 117-126; Carrocera y Camino, 1996: 57-60). Con esta asunción, la polémica pasó a centrarse en el ámbito cronológico de la ocupación castreña prerromana. Maya y Cuesta se inclinan por sostener una fecha del siglo VI a.C. para la muralla de la Campa Torres, frente a Camino, que la niega, a la vez que propone fechas en torno al siglo III a.C. para las cercas de Moriyón y La Campa. Este último autor ha defendido una periodización de la Edad del Hierro en Asturias (Camino, 1995a: 121-126; 1996; 1999: 151-161), distinguiendo una Edad del Hierro inicial, o Hierro I, definida en los poblados de Camoca, Campón y la primera fase de Moriyón, fechable en torno al siglo VI a.C., y una segunda Edad del Hierro, o Hierro II, definida en la segunda fase de Moriyón, en la que también incluye La CampaTorres, fechada entre el III a.C. y el cambio de era.

En los últimos tiempos han sido aportados nuevos datos cronológicos prerromanos, como ya hemos avanzado, referentes a los castros de San Chuis y Chao Samartín. Con ello se han incorporado a este debate yacimientos de laAsturias occidental.

Pese a este panorama historiográfico, que pudiera dar la impresión de que el conocimiento de la Edad del Hierro en Asturias ha avanzado considerablemente en la última década, la realidad arqueológica es lamentablemente diferente. Entre las deficiencias más preocupantes, destacaremos las siguientes.

La más destacada es la insuficiente superficie excavada en extensión de cada yacimiento. Salvo el Chao Samartín y San Chuís, en ningún otro castro han sido exhumadas varias estructuras completas de habitación. Esta circunstancia impide realizar estudios microespaciales y funcionales, al modo de los realizados, por ejemplo, en yacimientos castreños del Bierzo y la Cabrera leoneses (Corona de Corporales y Castrelín de San Juan de Paluezas).

En el caso de San Chuis la información publicada hasta la fecha es muy sintética, con casi total ausencia de descripciones, estratigrafías, planime-

T. P., 58, n. ${ }^{\circ} 2,2001$ 
trías detalladas y registro material recuperado. El análisis del poblado se ha limitado a vagas distinciones entre barrio indígena y barrio romanizado, a partir de la rnera morfología externa de las unidades de habitación, según predomine en ésta la línea curva o recta. En lo que toca a Chao Samartín, se encuentra todavía en una fase incipiente de publicación y estudio, por lo que habrá que esperar a informes más detallados.

Los poblados de la ría de Villaviciosa (Campón, Camoca, Moriyón) han sido sometidos a sondeos, más o menos amplios, que sólo en el tercero de ellos han abarcado una proporción significativa del poblado, permitiendo exhumar alguna cabaña completa (Camino, 1996: 28-29). No obstante, el grado de publicación descriptiva de estas estructuras es mínimo. Los informes existentes se limitan a someras indicaciones de la labor realizada, con alguna indicación estratigráfica y discusiones históricoculturales sobre periodización y filiación de los materiales exhumados. Se carece de toda planimetría que sitúe las estructuras exhumadas y permita inferir datos sobre urbanismo, organización social del espacio, evolución diacrónica del asentamiento, etc... Por otro lado, tanto en el Castiellu de Moriyón como en el Castiellu de Camoca y en el Campón se ha practicado la excavación de los rellenos de muralla (Camino, 1996: 29) y de los respectivos taludes defensivos (Camino, 1995a: 119-120, 1999: 152-153, perfiles superior e inferior). Esta práctica, que comporta la destrucción de una estructura constructiva de considerable entidad, lejos de haber aportado información esclarecedora, ha introducido elementos de confusión, pues la muestra radiocarbónica obtenida en Moriyón (CSIC 873) se han mostrado discordantes con las homólogas del resto del yacimiento, lo que obligó a su investigador a rechazarla tras las incoherencias advertidas por la crítica científica (Cuesta et alii, 1996: 246-247; Ríos y García de Castro, 1998: 80-81).

La superficie excavada en la Campa Torres se reparte en dos sectores: el exterior o Sur, inmediato a la muralla, y el interior o Norte, situado en la llanura interior del yacimiento, conocida propiamente como Campa Torres. En el primero, la excavación ha afectado fundamentalmente a la franja de terreno paralela al paramento interior de la muralla. Sus excavadores se limitaron a trazar sucesivos cortes rectangulares transversales a la misma, habiendo publicado hasta la fecha exclusivamente algunos perfiles de estos cortes, desconociéndose por el momento las planimetrías resultantes de es- tas intervenciones. De la lectura de los informes provisionales publicados se deduce que no ha sido exhumada en su totalidad ninguna estructura de habitación. Las reseñadas fragmentariamente se presentan como unidades aisladas de la dinámica estratigráfica, adscribiéndose sin mayor detalle a las fases generales de evolución del poblado definidas por los excavadores. Tampoco se describen individualizadamente los suelos de ocupación identificados, ni se registra el proceso de formación de la estratificación. Hasta el momento, las inferencias sedimentarias apuntadas no permiten establecer la historia concreta de los asentamientos humanos que en el Cabo Torres han tenido lugar.

En el sector interior de este yacimiento, la labor de los excavadores ha localizado solamente unos hipotéticos niveles prerromanos, consistentes en cubetas y hornos de fundición amortizados bajo pavimentos de las habitaciones de la fase romana. Dichas estructuras no han podido ser vinculadas a unidades y suélos de habitación coetáneos, circunstancia que ha sido explicada recurriendo al total arrasamiento sufrido por el hábitat indígena con motivo de la construcción del poblado romano (Maya y Cuesta, 1992: 150). Esta explicación, también esgrimida para justificar algunos de los hiatos estratigráficos del castro de San Chuis (Cuesta et alii, 1996. 234), no deja de requerir a su vez una causa suficiente para que el supuesto arrasamiento hubiese tenido lugar. En principio, y dado el coste energético que para sociedades no mecanizadas supone la demolición y extracción de escombros de la envergadura de la propuesta, y dado igualmente que la práctica habitual de estas sociedades a la hora de habilitar rasantes y plataformas consiste en rellenar en vez de vaciar, cabe dudar de la existencia de tal arrasamiento, al menos como explicación única del fenómeno.

A esta penuria de datos arqueológicos se yuxtaponen las elaboraciones historiográficas sobre la composición étnica de laAsturias prerromana basadas en el cotejo de las fuentes literarias grecorromanas, completadas con los datos provenientes de la epigrafía latina, la toponimia, la dialectología regional y la división administrativa imperial romana. En sus rasgos esenciales fue definida en la primera mitad del siglo XX por Menéndez Pidal (1906), Sánchez Albornoz (1929) y Schulten (1943). Sintéticamente, podría resumirse en una división del actual territorio asturiano en tres sectores de oeste a este. El occidental, delimitado grosso modo por la divisoria lingüística entre el Galle- 
go-Asturiano y elAsturiano Occidental, se adscribe al dominio galaico. La franja central, comprendida entre este límite y la divisoria de aguas SellaNalón, corresponde propiamente a los Astures. La franja oriental, las cuencas del Sella y Deva-Cares, se integra en el dominio Cántabro. La mayoría de los autores posteriores han asumido con algunos matices geográficos esta tripartición

Esta visión de la "Asturias Prerromana", ampliamente difundida en ambientes académicos y populares, presenta a los ojos de la crítica los siguientes inconvenientes:

- Ha sido obtenida mediante la combinación de datos heterogéneos, acríticamente aceptados y sin tener en cuenta las diferencias cronológicas de los mismos. Así, asistimos a la combinación de una supuesta división administrativa romana, obtenida a partir de los datos transmitidos por Plinio el Viejo (Naturalis Historia, III) y múltiples deducciones geográficas sin posible contraste-como divisorias de aguas, cursos fluviales...-, con los discutidos límites del repartimiento dialectal de la región-cuya profundidad cronológica nos es enteramente desconocida-, con datos procedentes de las fuentes epigráficas y unas referencias toponímicas faltas de concreción cronológica y arbitrariamente seleccionadas (Piedra Fita, Pedrafita, Piedrahita, Fitos, Jitos, Cofiño, Treviño...). Ninguno de los trazados divisorios sugeridos presenta pruebas indiscutibles de su validez. En ocasiones, incluso se recurre como elemento de contraste a los límites ofrecidos por las diócesis medievales, en un ejercicio lógico que reposa sobre una petición de principio: se supone y no se demuestra que las diócesis medievales son herederas de las divisiones administrativas romanas, que a su vez reproducen divisiones territoriales y étnicas preexistentes.

- Respecto a la utilización de las fuentes epigráficas, el primer obstáculo radica en su indefinición cronológica, pues ninguno de los epígrafes que contienen información étnica posee una fecha interna. Por otro lado, la propia contemplación de la distribución geográfica de hallazgos epigráficos contradice en algún caso la rígida compartimentación territorial que surge de esta historiografía. Por ejemplo, es tópica la mención del cauce del río Sella como límite entre astures y cántabros. En realidad, buena parte de los epígrafes con mención del grupo de los Orgenomesci, que Plinio el Viejo incluye entre los Cantabri, fueron hallados en tierras situadas al oeste de este río, es decir, en el territorio teórico de los Astures. Problema aparte constituiría la determinación exacta de este límite, pues el consenso historiográfico aparente por el que se fija su situación en el Sella, no ha resuelto aún el problema de la reducción del Salia citado por Mela (III.14; García y Bellido, 1947: 37) al Sella actual. Máxime cuando existen dos hidrónimos en Cantabria que se adaptan con mayor corrección lingüística a este étimo, como son Saja y Besaya. De hecho, el primero de ellos aparece citado bajo la forma Salia en documentos de los siglos X y XI. Por el contrario, documentación de la misma época atestigua que la forma Selia era la correspondiente al río asturiano (Sevilla Rodríguez, 1980: 67-72). En cualquier caso, e independientemente de que pueda fijarse algún día el trazado indudable de esta división administrativa, la realidad cronológica de ésta es indefectiblemente romana, respondiendo a necesidades de la administración imperial. Huelga por ello, suponer gratuitamente que la administración romana articula el territorio sometiéndose con fidelidad a unas hipotéticas fronteras étnico-culturales preexistentes. Pocas veces una argumentación similar pide principio de manera más clara. Ello sin recurrir al hecho cada vez más asentado en la investigación de que los corónimos latinos del tipo Lusitania, Celtiberia, Gallaecia...son por su naturaleza fluctuantes en su ubicación territorial y puramente genéricos en cuanto a su denotación étnico-geográfica. Es decir, responden a la percepción exterior de los geógrafos y funcionarios romanos, y no pueden ser interpretados como reflejo objetivo de las realidades a las que pretenden retratar (Pereira Menaut, 1984; Burillo, 1998). Son claros ejemplos del uso de perspectivas emic. Una simple contemplación geográfica de la extensión de estos corónimos permite verificar que ninguno de ellos comprende circunscripciones homogéneas, bien definidas por rasgos climáticos, topográficos o biológicos. Al contrario, integran territorios en los que las posibilidades de explotación y organización social del entorno son muy diversas, lo que forzosamente conduce a modelos de adaptación al medio muy diferentes, con necesarias implicaciones en el reflejo arqueológico de sus actividades. $\mathrm{Y}$ a este primer nivel, técnico-económico, de la organización social es al que se refiere el grueso de la información accesible directamente a la observación arqueológica.

- Por el momento, la arqueología no ha suministrado elemento alguno que aporte luz al problema. No se posee información cuantitativamente significativa como para suscribir ningún tipo de 
diferenciación histórico-cultural del territorio actualmente asturiano, pues, como hemos visto, el repertorio material de la Edad del Hierro en el territorio del Principado de Asturias, tanto de estructuras constructivas como de objetos muebles, es mínimo por el momento. Todo ello al margen de la incoveniencia de identificación de grupos étnicos basados en los conjuntos arqueográficos.

- Una cuestión pendiente de esclarecimiento definitivo es el llamativo contraste existente entre las calidades constructivas de la arquitectura de murallas y la arquitectura doméstica de los poblados del centro de la región. Las primeras muestran un dominio pleno de la técnica de cantería de la caliza, lo que prueba que la construcción de las cabañas con materiales perecederos no se debe a insuficiencia técnica. Esta circunstancia fuerza a buscar una explicación intencional en la opción técnica elegida por los habitantes de estos castros amurallados. Para responder adecuadamente a esta pregunta se requiere, en primer lugar, un conocimiento sustancialmente más profundo de las condiciones de habitabilidad de las dependencias domésticas, que permita valorar su resistencia a la erosión en un clima templado-húmedo, las hipotéticas ventajas respecto al empleo de mampostería, las necesidades de mantenimiento y su periodicidad, de forma que pueda determinarse su durabilidad media, $y$, en consecuencia, el ámbito cronológico que puedan abarcar en la vida de un poblado. En cualquier caso, dado que es regla general en los poblados excavados en el centro de la región la coexistencia de estos dos tipos de arquitectura, no es aceptable la idea de que la arquitectura doméstica no pétrea corresponde a ocupaciones "provisionales" del asentamiento.

El problema de la identificación material de la Edad del Hierro es tanto más grave cuanto que las ocupaciones definidas en los yacimientos excavados, lejos de atestiguar sobre permanencias de larga duración en el uso de los asentamientos, consisten estrictamente en hitos aislados dispersos entre vacíos ocupacionales. En ningún poblado se ha documentado una estratificación de larga duración, en la que pueda inferirse la continuidad multisecular en el poblamiento y su evolución diacrónica. Es decir, no conocemos ningún "tell" de la Edad del Hierro en Asturias. En el interior de las cabañas excavadas no se ha documentado una sucesión suficiente de suelos de ocupación que permita inferir la continuidad del hábitat. En principio cabe deducir que los horizontes de ocupación excavados constituyen el último momento de uso de las mismas.
Siempre se podrá argumentar que su formación fue precedida de la limpieza y vaciado de depósitos sedimentarios preexistentes. Ahora bien, esta hipótesis reposa sobre una petición de principio: si no hay huellas arqueológicas de los depósitos anteriores no hay manera de argumentar la fundación de las cabañas con anterioridad a los respectivos suelos de ocupación documentados. Sobran por lo tanto las especulaciones periodizadoras que pretenden sustentarse en este fragmentario registro. En este sentido, no resulta de fácil comprensión que hayan podido postularse relaciones de causalidad histórica entre la ocupación de la denominada Primera Edad del Hierro en Asturias y un fantasmal modelo de "economía mundial", según la cual el surgimiento de los poblados en la ría de Villaviciosa estaría en relación directa con explotaciones metalúrgicas insertas en un circuito comercial internacional, cuyo desmoronamiento explicaría el fin de esta etapa (Camino, 1999: 158-159).

En primer lugar, no se encuentra en el registro arqueológico publicado la huella de una actividad metalúrgica orientada a la producción masiva, seriada, estandarizada y comercializable. Tampoco han sido señalados los filones metalíferos hipotéticamente beneficiados, de los que se pueda inferir el alcance de su explotación. Mucho menos, el registro ha aportado testimonios que prueben la inserción de la comarca de la ría deVillaviciosa en los circuitos del sistema de "economía mundial". En síntesis, nos parece un puro ejercicio de voluntarismo subjetivista poner en paralelo los procesos históricos que condujeron, por un lado, a las formaciones sociales de los principados ibéricos en el sudeste de la Península Ibérica y célticos en el suroeste deAlemania (Frankenstein, 1997), y, por otro, a la aparición de los poblados castreños en la ría de Villaviciosa. En pocas ocasiones se puede observar tan claramente cómo el registro arqueológico es integrado, sin aparentes problemas, en construcciones teóricas absolutamente contradictorias con las inferencias objetivas que lícitamente cabe extraer de ese mismo registro.

\section{BIBLIOGRAFÍA}

Adán Álvarez, G.; Martínez Faedo, L. y Díaz García, L. (1994): "Limpieza estratigráfica del castro de Caravia (Caravia. Asturias): reconstrucción arqueológica-histórica”.Zephyrus, XLVII: 343-352.

Burillo Mozota, F. (1998): Los celtíberos. Etnias y Estados. Crítica. Barcelona. 
CAmino Mayor, J. (1992): “Excavaciones arqueológicas en castros de la Ría de Villaviciosa: un poblamiento de la Edad del Hierro". Excavaciones Arqueológicas en Asturias, 2 (1987-90): 137-144.

- (1995a): "Excavaciones arqueológicas en castros de la Ría de Villaviciosa. Apuntes para una sistematización de la Edad del Hierro". Excavaciones Arqueológicas en Asturias, 3 (1991-94): 117-126.

- (1996): "Una incursión na edá del fierro. El poblamientu castreñu de la ria de Villaviciosa". Asturies. Memoria encesa d'un pais, 2: 21-36.

- (1999): "Excavaciones arqueológicas en castros de la ría de Villaviciosa. Precisiones cronológicas". Excavaciones Arqueológicas en Asturias 4 (1995-1998): 151161.

- (2000): "Revisión cronológica de la muralla del castro de Campa Torres (Gijón). Revista de Arqueología, 228: 6-12.

Carballo Arceo, L.X. (1990): "Los castros de la cuenca media del río Ulla y sus relaciones con el medio físico". Trabajos de Prehistoria, 47: 161-199.

Carrocera Fernández, E. (1987a): "Castro de Coaña". Arqueología, 84-85: 28.

- (1987b): "Castro de La Escrita", Arqueología, 84-85: 25.

- (1990a): "La cultura castreña en Asturias". Historia de Asturias I. Prensa Asturiana. Oviedo: 121-136.

- (1990b): "El castro de San Isidro: informe de las excavaciones arqueológicas 1986". Excavaciones Arqueológicas en Asturias, 1 (1983-86): 157-162.

- (1990c): "El horizonte cultural castreño del occidente asturiano y sus relaciones exteriores". Gallaecia, 12: $135-138$

- (1992): "Excavaciones arqueológicas en el Occidente de Asturias (campañas de 1987-90)". Excavaciones Arqueológicas en Asturias, 2 (1987-90): 129-136.

- (1994): "Estudio crítico de la cultura castreña asturiana". $1^{\circ}$ Congresso de Arqueología Peninsular (Porto 1993). Trabalhos de Antropología e Etnología, XXXIV, (3-4): 213-221.

- (1995a): "El territorio de los astures: los castros". As tures. Pueblos y culturas en la frontera del Imperio Romano (Gijón, 1995): 53-65. Asociación Astures. Gijón.

Carrocera Fernández, E. y Camino Mayor, J. (1996): "La Edad del Hierro en el territorio histórico de los Astures o la realidad de un espacio administrativo romano". Los Finisterres Atlánticos en laAntigüedad. Electa. Gijón: 57-60.

Carrocera Fernández, E. y Requejo Pagés, O. (1989): "Producciones cerámicas tardías en villas y castros asturianos". Boletín deArqueología Medieval, 3: 21-30.

Cuesta, F.; Jordá Pardo, J.; Maya, J.L. y Mestres, J.S. (1996): "Radiocarbono y cronología de los castros asturianos". Zephyrus, 49: 225-270.

Escortell Ponsoda, M. y Maya González, J.L. (1972):
"Materiales de El Pico Castiello, Siero, en el Museo Arqueológico Provincial”. Archivum, 22: 37-48.

FERnÁNDEZ-PosSE, M. D. (1998): La investigación protohistórica en la Meseta y Galicia. Síntesis. Madrid.

Fernández Posse, Ma .D. y Sánchez-Palencia, F.J. (1988): la Corona y el castro de Corporales II. Campaña de 1983 y prospecciones en La Cabrera y La Valderia (León). Excavaciones Arqueológicas en España, 153. Ministerio de Cultura. Madrid.

- (1998): "Las comunidades campesinas en la cultura castreña". Trabajos de Prehistoria, 55: 127-150.

Frankenstein, S. (1997): Arqueología del Colonialismo. El impacto fenicio y griego en el sur de la Península Ibérica y en el Suroeste de Alemania. Crítica. Barcelona.

GaRCía Y BELlido, A. (1945): España y los españoles hace 2000 años según la "Geografía” de Strábon. Espasa Calpe. Madrid.

- (1947): La España del siglo I de nuestra era (según P. Mela y C. Plinio). Espasa Calpe. Madrid.

GonZÁlez y FernÁndez VALLES, J.M. (1966): “Catalogación de los castros asturianos". Archivum, XXVI: 99-132.

- (1973): "Castros asturianos del sector lucense y otros no catalogados". Cuadernos de Estudios Gallegos, XXVIII: 143-152.

JordÁ Cerdé, F. (1985): “Allande: castro de San Chuís". Arqueología, 83.

- (1987): "Allande: castro de San Amís" (sic). Arqueología, 84-85: 25.

- (1990): "Informe preliminar sobre las excavaciones arqueológicas en el castro de San Chuis (Beduledo, Allande).Asturias. Campaña de 1986". Excavaciones Arqueológicas en Asturias, 1 (1983-86): 153-156.

Jordá Cerdá, F.; Manzano Hernández, M.P.; Jordá ParDo, J.F.; GonzÁlez-Tablas, F.J.; Carrocera, E. y BÉCARES, J. (1989): "El castro asturiano de San Chuis". Revista de Arqueología, 95: 38-48.

JoRdÁ PARDO, J. (1990): "El medio geológico y su explotación en el castro de San Chuis (Allande, Asturias)". Boletín Geológico y Minero, 101-5: 780-791.

Jordá Pardo, J.F. y García Martínez, F. (1999): "Investigaciones arqueológicas en el castro de San Chuis (Allande, Asturias): últimos trabajos y memoria final (Estratigrafía isotópica y trabajos desarrollados durante 1997)". Excavaciones Arqueológicas en Asturias, 4 (1995-1998): 137-150.

LóPEz GonZÁlez, L.F.; Álvarez GonZÁlez, Y. y LóPEZ MARcos, M.A. (1999): "Excavación en el castro de Llagú, Latores (Oviedo, 1998). Avance de los resultados". Excavaciones arqueológicas en Asturias, 4 (1995-1998): 237-252

Llano Roza de Ampudia, A. DE (1919): El libro de Caravia. IDEA. Oviedo.

Manzano Hernández, M.P. (1986-87): “Avance sobre la cerámica común del castro de San Chuis (Allande, Asturias)". Zephyrus, 39-40: 397-410.

Maya González, J.L. (1988): La cultura material de los

T. P., 58, n. $^{\circ} 2,2001$ 
castros asturianos. Estudios de la Antigüedad, 4-5. Universidad Autónoma de Barcelona. Barcelona.

- (1994): "El factor indoeuropeo y su influencia en el NO de la Península Ibérica: el caso asturiano". Aquitania, XII: $297-321$.

- (1996): "Cerámicas de época celtibérica en la Edad del Hierro Asturiana". Pyrenae, 27: 287-294.

- (1999): "La Campa Torres (Gijón, Asturias) ¿Oppidum Noega? Un ejemplo de urbanismo híbrido". En A. Rodríguez Colmenero (coord.): Los orígenes de la ciudad en el Noroeste hispánico (Lugo, 1996): 945-978. Lugo.

Maya González, J.L. y Cuesta Toribio, F. (1990): "Excavaciones en la Campa Torres". Excavaciones arqueológicas en Asturias, 1 (1983-1986): 163-164.

- (1992): "Excavaciones en la Campa Torres (19861990)". Excavaciones Arqueológicas en Asturias, 2 (1987-1990):145-152.

- (1995a): "Estratigrafía e interpretación histórica de la Campa Torres (1991-1994)"'. Excavaciones Arqueológicas en Asturias, 3 (1991-1994): 105-116.

- (1996): "Cuestiones cronológicas y comercio en la Campa Torres (Gijón, Asturias)". Los finisterres atlánticos en la Antigüedad. Electa. Gijón: 61-68.

- (1999): "Cronoestratigrafía de la Campa Torres, Gijón (1995-1998)". Excavaciones Arqueológicas en Asturias, 4 (1995-1998): 125-135.

MAYA, J.L. y MESTRES, J.S. (1998): "Dataciones prerromanas del Castiellu de Llagú (Latores, Oviedo)". Revista de Arqueología, 195: 6-11.

Menéndez Pidal, R. (1906): "El dialecto leonés". Revista de Archivos, Bibliotecas y Museos

Orejas Saco del Valle, A. (1996): Estructura social y territorio. El impacto romano en la cuenca noroccidental del Duero. Anejos del Archivo Español deArqueología, XV. CSIC. Madrid.

Pereira Menaut, G. (1984): "La formación histórica de los pueblos del norte de España". Veleia, 1: 271-287.

Ríos GonZÁlez, S. (2000): "Consideraciones funcionales y tipológicas en torno a los baños castreños del NO de la Península Ibérica". Gallaecia, 19: 93-124.

Ríos González, S. y García de Castro Valdés, C. (1998): Asturias castreña. Trea. Gijón.

SÁnCheZ Albornoz, C. (1929): 'Divisiones tribales y administrativas del solar del Reino de Asturias en la época romana". Boletín de la Real Academia de la Historia, XCV: 315-395.

Sánchez Palencia, F.J. y Fernández Posse, M.D. (1985): La Corona y el castro de Corporales (Truchas, León. Campañas de 1978 a 1981). Excavaciones Arqueológicas en España, 141. Ministerio de Cultura. Madrid.

Schulten, A. (1943): Los Cántabros y Astures y su guerra con Roma. Espasa Calpe. Madrid.

Sevilla Rodríguez, M. (1980): Toponimia indoeuropea prelatina en Asturias. IDEA. Oviedo.

Villa ValdÉs, A. (1998a): "Excavaciones en el castro del Chao Samartín (Campaña de 1995)". En A. Rodríguez Colmenero (coord.): Los orígenes de la ciudad en el Noroeste hispánico (Lugo 1996): 979-991. Lugo.

- (1998b): "El castro del Chao Samartín". Revista de Arqueología, 211: 32-41.

- (1999a): "Castro del Chao Samartín (Grandas de Salime): tres años de investigación arqueológica (19951998)". Excavaciones Arqueológicas en Asturias, 4 (1995-1998): 111-123.

- (1999b): "Chao Samartín. Entre la tierra y el tiempo". Asturies. Memoria encesa d'un pais, 6. 